\title{
Assessment of drug resistance associated genetic diversity in Mauritanian isolates of Plasmodium vivax reveals limited polymorphism
}

Jemila Mint Deida 1,2, Yacoub Ould Khalef, Emal Mint Semane ${ }^{4}$, Mohamed Salem Ould Ahmedou Salem', Hervé Bogreau ${ }^{5,6,7}$, Leonardo Basco ${ }^{6}$, Ali Ould Mohamed Salem Boukhary ${ }^{1,6^{*}}$ and Rachida Tahar ${ }^{2}$

\begin{abstract}
Background: Plasmodium vivax is the predominant malaria species in northern Mauritania. Molecular data on P. vivax isolates circulating in West Africa are scarce. The present study analysed molecular markers associated with resistance to antifolates (Pvdhfr and Pvdhps), chloroquine (Pvmdr1), and artemisinin (Pvk12) in P. vivax isolates collected in two cities located in the Saharan zone of Mauritania.

Methods: Blood samples were obtained from P. vivax-infected patients recruited for chloroquine therapeutic efficacy study in 2013 and febrile patients spontaneously consulting health facilities in Nouakchott and Atar in 2015-2016. Fragments of Pvdhfr (codons 13, 33, 57, 58, 61, 117, and 174), Pvdhps (codons 382, 383, 512, 553, and 585), Pvmdr1 (codons 976 and 1076) and PVk12 (codon 552) genes were amplified by PCR and sequenced.

Results: Most of the isolates in Nouakchott (126/154, 81.8\%) and Atar (44/45, 97.8\%) carried the wild-type Pvdhfr allelic variant (IPFSTSI). In Nouakchott, all mutants (28/154; 18.2\%) had double Pvdhfr mutations in positions 58 and 61 (allelic variant IPFRMSI), whereas in Atar only 1 isolate was mutant (S117N, allelic variant IPFSTNI). The wild-type Pvdhps allelic variant (SAKAV) was found in all tested isolates (Nouakchott, $n=93 ;$ Atar, $n=37$ ). Few isolates in Nouakchott $(5 / 115,4.3 \%)$ and Atar $(3 / 79,3.8 \%)$ had the mutant Pvmdr1 allele 976F or 1076L, but not both, including in pretreatment isolates obtained from patients treated successfully with chloroquine. All isolates (59 in Nouakchott and 48 in Atar) carried the wild-type V552 allele in Pvk12.
\end{abstract}

Conclusions: Polymorphisms in Pvdhfr, Pvdhps, Pvmdr1, and Pvk 12 were limited in P. vivax isolates collected recently in Nouakchott and Atar. Compared to the isolates collected in Nouakchott in 2007-2009, there was no evidence for selection of mutants. The presence of one, but not both, of the two potential markers of chloroquine resistance in Pvmdr in pre-treatment isolates did not influence the clinical outcome, putting into question the role of Pvmdr1 mutant alleles $976 \mathrm{~F}$ and $1076 \mathrm{~L}$ in treatment failure. Molecular surveillance is an important component of $P$. vivax malaria control programme in the Saharan zone of Mauritania to predict possible emergence of drug-resistant parasites.

Keywords: Malaria, Sahara, Drug resistance, Chloroquine, Sulfadoxine-pyrimethamine, Artemisinin

\footnotetext{
*Correspondence: alimedsalem@gmail.com

${ }^{1}$ Unité de Recherche Génome et Milieux (JEAI), Faculté des Sciences et Techniques, Université de Nouakchott Al-Aasriya, Nouveau campus universitaire, BP 5026 Nouakchott, Mauritania

Full list of author information is available at the end of the article
} 


\section{Background}

Both Plasmodium falciparum and Plasmodium vivax are endemic in Mauritania with approximately 300,000 malaria cases reported in 2017 [1]. In the northern Saharan zone of Mauritania, particularly in Nouakchott, the capital city of the country, and Atar, the provincial capital of Adrar region, malaria transmission is seasonal, and $P$. vivax has been shown to be the main causative species of malaria parasite [2-4]. Infections caused by $P$. vivax have been considered for a long time as benign. Recently, several prospective studies recognized that $P$. vivax may be responsible for significant morbidity and even severe disease leading to mortality in endemic areas [5]. In the absence of an effective malaria vaccine, the use of insecticide-impregnated bed nets and antimalarial drug administration remain the only ways to prevent or treat the disease and reduce the probability of transmitting the parasite to Anopheles mosquitoes [6]. However, in many malaria-endemic countries, including Africa, the control strategy based on anti-malarial drugs has been facing the problem of parasite strains resistant to chloroquine, amodiaquine, antifolates, and mefloquine. In some countries, artemisinin resistance, including resistance to artemisinin-based combination therapy (ACT) dihydroartemisinin-piperaquine, has also emerged and spread [7-10]. To prevent, delay, and overcome the emergence of multidrug-resistant parasites, ACT has been recommended since 2001 for the treatment of uncomplicated malaria in endemic countries [11].

The mechanisms of resistance to antimalarial drugs, particularly in P. falciparum, have been studied for decades, but for some drugs, the mechanisms have not been fully elucidated. At least seven $P$. falciparum genes have been associated with drug resistance, namely $P$. falciparum chloroquine resistance transporter $(P f c r t)[12,13]$, P. falciparum multi-drug resistance 1 (Pfmdr1) [14-16], P. falciparum dihydrofolate reductase (Pfdhfr) [17-19], $P$. falciparum dihydropteroate synthase (Pfdhps) [19-22], $P$. falciparum cytochrome $b$ (Pfcytb) $[23,24]$ and P. falciparum sodium/hydrogen exchanger 1 (Pfnhe-1) [25, 26]. More recently, several mutations in the Kelch propeller domain of PF3D7_1343700 (Pfk13) were proposed to be directly responsible for artemisinin resistance in Cambodian isolates [27]. In addition to single nucleotide polymorphisms (SNPs), gene copy number may also be associated with resistance to certain drugs $[14,16]$.

In $P$. vivax, orthologous genes have been identified. Mutations in $d h f r$ and dhps confer resistance to pyrimethamine and sulfadoxine, respectively, in both $P$. falciparum and P. vivax [22, 28-30]. Mutations in Pfcrt gene are associated with chloroquine resistance in $P$. falciparum whereas in $P$. vivax the role of Pvcrt-o (PfCRT-like protein, $P$. vivax orthologue also called $p v c g 10)$ mutations, insertion, gene copy number, or expression levels in conferring chloroquine resistance is not yet clear [31-36]. In P. vivax, mutations in Pvmdr1 gene may be associated with resistance to chloroquine and amodiaquine [33, 37, 38].

The first molecular surveillance of $P$. vivax in Mauritania was conducted with isolates collected in 2007-2009 in Nouakchott, the capital city [3]. The present study is a follow-up molecular surveillance of $P$. vivax resistance in Nouakchott and Atar, both of which are situated in the Saharan zone of Mauritania, using P. vivax isolates collected between 2013 and 2016. As in the earlier study [3], polymorphisms in $P v d h f r, P v d h p s$, and $P v m d r 1$ were analysed in the present study. In addition, $P$. vivax kelch propeller domain located on chromosome 12 (Pvk12), which was shown to be homologous to Pfk13 in 2015, was analysed in the present study [39]. Pvcrt-o gene was not sequenced in this study because there is no association between Pvcrt-o mutations and chloroquine resistance $[31,32]$.

\section{Methods}

Patients and blood sample collection

Blood samples used in the present study were collected from $P$. vivax-infected patients recruited for chloroquine therapeutic efficacy study conducted in Nouakchott and Atar in 2013 [40] and febrile patients spontaneously consulting health centres and hospitals and screened for malaria using rapid diagnostic test for malaria (SD Bioline $P$. falciparum histidine-rich protein 2 and $P$. vivax plasmodial lactate dehydrogenase antigen rapid diagnostic test; Standard Diagnostics, Inc., Yongin, Republic of Korea) in Nouakchott and Atar in 2015-2016 (Fig. 1). Two or three drops of fingerprick capillary blood (approximately 150-200 $\mu \mathrm{L}$ ) were spotted directly on Whatman 3MM blotting paper (GE Healthcare Life Sciences, Bucks, UK), dried, and stored in individual sealed plastic bag at $-20^{\circ} \mathrm{C}$ until use.

\section{PCR and sequencing of drug resistance genes}

Parasite DNA was extracted from Whatman ${ }^{\circledR} 3 \mathrm{MM}$ papers by Chelex ${ }^{\circledR}$-saponin method [41]. Plasmodium species was identified by nested PCR targeting cytochrome $b$ gene [42]. The presence of $P v k 12$ mutation (V552I) observed in Cambodian P. vivax isolates was analysed using PCR protocol described by Popovici et al. [39].

Mutations associated with drug resistance in $P v d$ hfr, Pvdhps, and Pvmdr1 genes were investigated using slightly modified nested PCR protocols described earlier [3]. The sequences of specific primers are presented in Table 1 . The reaction mixture for the primary PCR amplification consisted of $10 \mu \mathrm{L}$ of DNA template, $0.2 \mathrm{mM}$ 

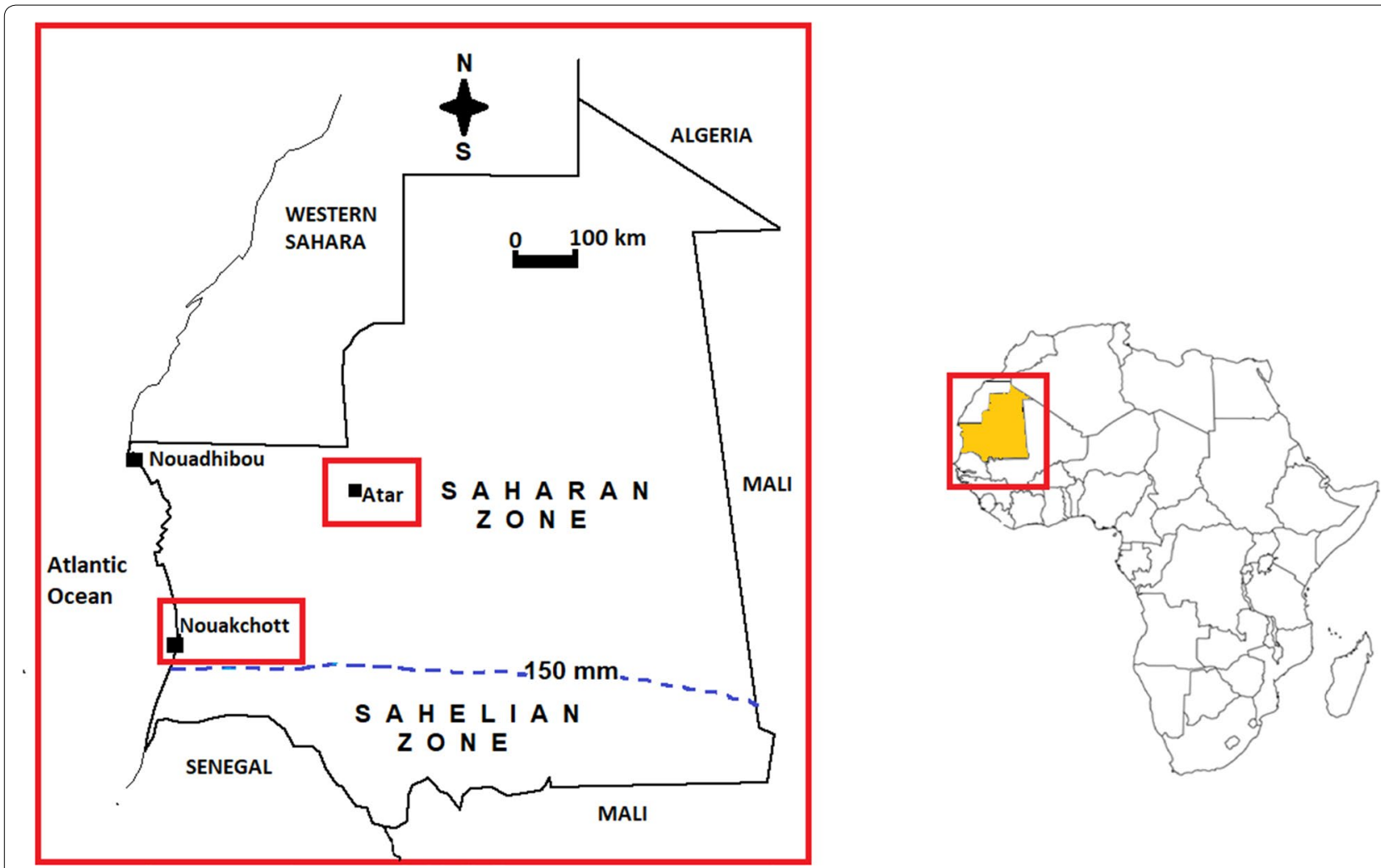

Fig. 1 Map of Mauritania showing the study sites. The dotted line denotes $150 \mathrm{~mm} /$ year isohyet which indicates the southern limit of the Saharan zone

dNTP, $1.5 \mathrm{mM} \mathrm{MgCl}_{2}, 0.25 \mu \mathrm{M}$ of primer pairs, $1 \times$ reaction buffer and $2.5 \mathrm{U} / \mu \mathrm{L}$ Taq DNA polymerase (Bioline, France, Meridian Bioscience Europe, Paris, France) in a final volume of $50 \mu \mathrm{L}$.

Nested PCR amplifications were performed using a thermal cycler (Eppendorf 950000015 Mastercycler Gradient Thermal Cycler; Hinz GmbH, Hamburg, Germany). The following program was used to amplify $P v d h f r$, Pvdhps, and Pvmdr1 genes: initial denaturation at $95{ }^{\circ} \mathrm{C}$ for $5 \mathrm{~min}$ followed by 45 cycles of denaturation at $95^{\circ} \mathrm{C}$ for $1 \mathrm{~min}$, annealing at $53{ }^{\circ} \mathrm{C}$ for $1 \mathrm{~min}$ and elongation at $72{ }^{\circ} \mathrm{C}$ for $1 \mathrm{~min}$, and the final elongation step of $72{ }^{\circ} \mathrm{C}$ for $10 \mathrm{~min}$. For the secondary amplification, $2 \mu \mathrm{L}$ of the primary PCR product was used as DNA template. The thermal cycling program and PCR mixture were identical to those of the primary PCR, except for the annealing temperature which was set at $65^{\circ} \mathrm{C}$ and the volume of DNA template.

The products of the secondary PCR were visualized by electrophoresis on a $1 \%$ agarose gel. The PCR products were purified using Wizard ${ }^{\circledR} \mathrm{SV}$ gel and PCR clean-up system (Promega Corp, Fitchburg, WI) according to the manufacturer's instructions. DNA sequencing of the PCR products was performed by Eurofins Genomics (Les Ulis,
France) using BigDye Terminator v3.1 cycle sequencing kit (Applied Biosystems Courtaboeuf, France) and ABI 3730XL sequencer. Sequences were read using Chromas DNA sequencing software (Technelysium Pty Ltd., South Brisbane, Australia) and aligned using Clustal X2 software (Conway Institute, University College Dublin, Dublin, Ireland) to search for SNPs. Polymorphisms were identified in both forward and reverse strands by comparing the sequences to the reference sequences of $P v d$ hfr (GenBank accession no X98123), Pvdhps (GenBank accession no AY186730), Pvmdr1 (Genbank accession no AY618622), and Pvk12 (PVX_083080).

\section{Results}

Among blood samples collected in Nouakchott and confirmed positive by rapid diagnostic test, the molecular markers of drug resistance were analysed for the following numbers of isolates: 154 for Pvdhfr, 93 for Pvdhps, 115 for $P v m d r 1$, and 59 for Pvk12 (Table 2). For Pvdhfr, a large majority of isolates $(126 / 154,81.8 \%)$ had wildtype alleles at positions $13,33,57,58,61,117$, and 173 (wild-type allelic variant IPFSTSI). Twenty-eight isolates (18.2\%) were double mutants with 58R and 61M (mutant 
Table 1 Primers used to amplify Pvdhfr, Pvdhps, Pvmdr1, and Pvk12

\begin{tabular}{|c|c|c|}
\hline Gene & Primer sequences & $\begin{array}{l}\text { Amplicon } \\
\text { size (bp) }\end{array}$ \\
\hline \multicolumn{3}{|l|}{ Pvdhfr } \\
\hline \multirow[t]{2}{*}{1 st PCR } & Forward: 5'-ACCCTTCCATAGGGAGTCCACTT-3' & 961 \\
\hline & Reverse: 5'-CGCATTGCAGTTCTCCGAA-3' & \\
\hline \multirow[t]{2}{*}{ 2nd PCR } & Forward: 5'-CCCCACCACATAACGAAGTAG-3' & 632 \\
\hline & Reverse: 5'-GCCGTTGATCCTCGTGAAG-3' & \\
\hline \multicolumn{3}{|l|}{ Pvdhps } \\
\hline \multirow[t]{2}{*}{ 1st PCR } & Forward: 5'-GGAAGCCATTCGCTCAACTTATAA-3' & 970 \\
\hline & Reverse: 5'-CGTCAGTTTACCCTCCCCGTT-3' & \\
\hline \multirow[t]{2}{*}{ 2nd PCR } & Forward: 5'-GATGGCGGTTTATTTGTCGAT-3' & 767 \\
\hline & Reverse: 5'-GCCTCCCCGCTCATCAGTCT-3' & \\
\hline \multicolumn{3}{|l|}{ Pvmdr1 } \\
\hline \multirow[t]{2}{*}{ 1st PCR } & $\begin{array}{l}\text { Forward: 5'-GCGAACTCGAATAAGTACTCCCTC } \\
\text { TA-3' }\end{array}$ & 762 \\
\hline & Reverse: 5'-GGCGTAGCTTCCCGTAAATAAA-3' & \\
\hline \multirow[t]{2}{*}{ 2nd PCR } & Forward: 5'-GGATTGCTGTCAGCACATATTAACA-3' & 547 \\
\hline & Reverse: 5'AGAGGGATTTCATAAAGTCATCCACT-3' & \\
\hline \multicolumn{3}{|c|}{ 皮 } \\
\hline \multirow[t]{2}{*}{ 1st PCR } & Forward: 5'-ATCCAACAGCATTTCCAACT-3' & 2108 \\
\hline & Reverse: 5'-CAATTAAAACGGAATGTCCA-3' & \\
\hline \multirow[t]{2}{*}{ 2nd PCR } & Forward: 5'-ACCACGTGACGAGGGATAAG-3' & 1015 \\
\hline & Reverse: 5'-AAAACGGAATGTCCAAATCG-3' & \\
\hline
\end{tabular}

a Primer sequences and amplicon sizes were from Mint Lekweiry et al. [3] for Pvdhfr, Pvdhps and Pvmdr1 and Popovici et al. [39] for Pvk12

Table 2 Prevalence of Pvdhfr, Pvdhps, Pvmdr1, and Pvk12 allelic variants in Nouakchott and Atar, Mauritania

\begin{tabular}{|c|c|c|c|}
\hline Gene & Allelic variant ${ }^{a}$ & Nouakchott n/N (\%) & Atar n/N (\%) \\
\hline \multirow[t]{3}{*}{ Pvdhfr } & IPFSTSI (wild-type) & 126/154 (81.8) & 44/45 (97.8) \\
\hline & |PFRMSI & 28/154 (18.2) & 0 \\
\hline & $\mid$ PFSTN| & 0 & $1 / 45(2.2)$ \\
\hline Pvdhps & SAKAV (wild-type) & 93/93 (100) & $37 / 37(100)$ \\
\hline \multirow[t]{3}{*}{ Pvmdr1 } & YF (wild-type) & 110/115 (95.7) & 76/79 (96.2) \\
\hline & $\underline{\mathbf{F}} F$ & $5 / 115(4.3)$ & $1 / 79(1.3)$ \\
\hline & $Y \underline{\mathbf{L}}$ & 0 & $2 / 79(2.5)$ \\
\hline \multirow[t]{2}{*}{ Pvk12 } & V552 (wild-type allele) & $59 / 59(100)$ & $48 / 48(100)$ \\
\hline & 5521 & 0 & 0 \\
\hline
\end{tabular}

$n$ number of isolates with the given allelic variant $N$ total number of isolates analysed

a Allelic variants are based on the following codons: $13,33,57,58,61,117$, and 174 for Pvdhfr; 382, 383, 512, 553, and 585 for Pvdhps; and 976 and 1076 for Pvmdr1. The amino acid substitution V552l in Pvk12 was suggested to be a potential marker for artemisinin-resistant $P$. vivax in Cambodia [39]

allelic variant IPFRMSI). All isolates (93/93, 100\%) had the wild-type Pvdhps allelic variant (SAKAV). Sequencing of the Pvmdr1 gene revealed that a large majority of isolates $(110 / 115,95.7 \%)$ were of wild-type at positions
976 and 1076, while only 5 isolates $(4.3 \%)$ had the mutant allele 976F. None of the isolates carried the mutant 1076L allele. All isolates $(59 / 59,100 \%)$ collected in Nouakchott had the wild-type allele V552 in Pvk12 (Table 2).

With respect to $P$. vivax-infected blood samples collected in Atar and confirmed to be positive by rapid diagnostic test for malaria, 45, 37, 79, and 48 amplification products were analysed for $P v d h f r, P v d h p s, P v m d r 1$ and $P v k 12$, respectively (Table 2). For $P v d h f r$, most isolates $(44 / 45,97.8 \%)$ exhibited wild-type alleles in codons $13,33,57,58,61,117$, and 173 , giving the allelic variant IPFSTSI. Only one isolate (2.2\%) carried a single S117N mutation (mutant allelic variant IPFSTNI). For Pvdhps, all isolates $(37 / 37,100 \%)$ were of wild-type allelic variant (SAKAV) at positions 382, 383, 512, 553 and 585. Most isolates $(76 / 79,96.2 \%)$ carried wild-type Y976 and F1076 codons in the Pvmdr1 gene. Only three isolates (3/79, $3.8 \%)$ had $976 \mathrm{~F}(\mathrm{n}=1$ isolate) or $1076 \mathrm{~L}(\mathrm{n}=2)$ mutant alleles. As in Nouakchott, all isolates $(48 / 48,100 \%)$ were characterized to carry the wild-type V552 allele in $P v k 12$ (Table 2).

\section{Discussion}

In Mauritania, the treatment of uncomplicated malaria had been based on chloroquine and sulfadoxinepyrimethamine (SP) as the first- and second-line drugs until 2006, respectively. Following the emergence and spread of chloroquine-resistant $P$. falciparum in West Africa [43], the Mauritanian health authorities adopted, in 2006, a new therapeutic strategy for the management of malaria cases based on ACT (using either artesunateamodiaquine or artemether-lumefantrine) as the firstline treatment for all malaria cases without distinction of Plasmodium species. This national drug policy was adopted to conform to the WHO guidelines for African countries and was not a decision based on previous clinical studies demonstrating chloroquine-resistant $P$. falciparum in Mauritania.

Unlike $P$. falciparum, which is the predominant Plasmodium species in Africa, molecular data on $P$. vivax are scarce to non-existent in most West African countries. The Saharan zone of Mauritania is an exception [44, 45]. The results of the present study showed that mutations in $P v d$ hfr, Pvdhps, Pvmdr1 and Pvk12 occur in some P. vivax isolates collected recently in the Saharan zone of Mauritania. It was also observed that in Pvdhfr, a marker known to accumulate mutations at specific codons and increase the level of resistance to pyrimethamine, the number of mutations in a mutant isolate was limited to two, and the key $P v d h f r$ S117N substitution was observed in a single isolate from Atar. These results are in general agreement with the previous study conducted in isolates collected in 2007-2009 in Nouakchott [3]. In that study, only $12 \%$ (10 of 86 ) of isolates 
were mutants carrying double mutations S58R and S117N, and, as in the present study, none of the isolates analysed earlier $(\mathrm{n}=94)$ had mutations in Pvdhps. For more than a decade, the use of SP has been restricted to pregnant women for intermittent preventive treatment (IPTp) in Mauritania, as well as in children for seasonal malaria chemoprevention (amodiaquine + SP) in some African countries in the Sahelian zone. Both of these preventive strategies are directed against $P$. falciparum. The use of SP to treat $P$. vivax malaria is not recommended due to its inherent resistance or lower susceptibility to antifolates [46]. In practice, some pregnant Mauritanian women under IPTp in the Saharan zone are exposed to the risk of $P$. vivax infection. Although prospective clinical studies would be required to confirm the benefit of IPTp even against $P$. vivax, molecular data tend to support SP efficacy against $P$. vivax.

The earlier molecular study in Nouakchott showed that most isolates $(75 / 103,73 \%)$ had Y976 wild-type Pvmdr1 allele, as in the present study $(110 / 115,95.7 \%)$ [3]. However, that study showed a high proportion $(98 \%)$ of mutant F1076L allele in Pvmdr1, whereas in the present study, mutation was absent in codon 1076. The origin of this discrepancy is unknown. This observation calls for further molecular monitoring in Nouakchott. Pvmdr1 Y976F and F1076L mutations were suggested to be associated with chloroquine and amodiaquine resistance [33, $37,38]$. However, several in vitro and clinical studies have failed to confirm the association between Pvmdr1 mutations and drug resistance [47-53]. In the present study, among 115 and 79 isolates with Pvmdrl sequences in Nouakchott and Atar, 51 and 48 were pre-treatment blood samples from patients treated with chloroquine in 2013, respectively. In many patients enrolled in chloroquine therapeutic efficacy studies, parasitaemia was cleared on or before day 3 , and none of the patients had parasitaemia on day 7 [40]. The outcome was adequate clinical and parasitological response in all patients on day 28. These results suggest that the presence of one of the two mutant Pvmdr1 alleles (i.e., 976F or 1076L, but not both) is not associated with chloroquine treatment failure in Nouakchott and Atar. It remains unclear whether both 976F and 1076L are required for chloroquine treatment failure since none of the isolates analysed in the present study carried the double mutations in Pvmdr1. Further clinical and molecular studies are required to assess the relevance of Pvmdr1 mutations in chloroquine resistance, in particular in African countries, such as Ethiopia, where chloroquine-resistant $P$. vivax occurs [54-57].

Artemisinin-resistant $P$. falciparum occurs in Southeast Asia, and resistance seems to be conferred by specific mutations in the propeller domain of Kelch 13 (K13; PF3D7_1343700) [27]. In P. vivax, Pvk12 was identified as the homologous gene of $P f k 13$ [39]. At present, there is no molecular indication that $P v k 12$ undergoes a high degree of mutations as its P. falciparum homolog, even in Southeast Asia [39, 58-60]. The sequence data of Mauritanian $P$. vivax isolates also indicate the absence of polymorphism in the $P v k 12$ gene fragment that was amplified and analysed. Moreover, clinical and in vitro studies carried out so far do not suggest artemisinin resistance in P. vivax. Further molecular surveillance is warranted to anticipate the possible emergence of artemisinin-resistant $P$. vivax around the world.

\section{Conclusions}

Few Mauritanian $P$. vivax isolates were characterized to carry mutations in Pvdhfr, Pvdhps, Pvmdr1, and Pvk12 markers. The molecular data are in general agreement with the high clinical efficacy of chloroquine previously demonstrated in Nouakchott and Atar and with an earlier study on isolates collected in 2007-2009 in Nouakchott, suggesting that mutations in these molecular markers of drug resistance are not being selected. Due to the unavailability of chloroquine in the official drug outlets of the country, $P$. vivax infections have been treated with ACT over more than a decade. This may explain, at least in part, the absence of selection of mutant $P$. vivax parasites. Molecular surveillance of $P$. vivax is an important component of malaria control in northern Mauritania where this parasite species is predominant.

\section{Abbreviations}

ACT: arteminisin-based combination therapy; IPTp: intermittent preventive treatment in pregnancy; Pfcrt: P. falciparum chloroquine resistance transporter; Pfcytb: P. falciparum cytochrome b; Pfdhfr: P. falciparum dihydrofolate reductase; Pfdhps: P. falciparum dihydropteroate synthase; Pfk 13: P. falciparum Kelch 13; Pfmdr1: P. falciparum multi-drug resistance 1; Pfnhe-1: P. falciparum sodium/ hydrogen exchanger 1; Pvcrt-o: Plasmodium vivax chloroquine resistance transporter orthologue; Pvdhfr: Plasmodium vivax dihydrofolate reductase; Pvdhps: Plasmodium vivax dihydropteroate synthase; Pvk12: Plasmodium vivax Kelch 12; Pvmdr1: Plasmodium vivax multidrug resistance 1; SNP: single nucleotide polymorphism; SP: sulfadoxine-pyrimethamine; WHO: World Health Organization.

\section{Authors' contributions}

JMD conducted the field study and performed laboratory experiments. EMS, YOK and MSOAS supervised the clinical studies. HB, LKB, AOMSB and RT conceived the study design and wrote the manuscript. All authors read and approved the final manuscript.

\footnotetext{
Author details

${ }^{1}$ Unité de Recherche Génome et Milieux (JEAI), Faculté des Sciences et Techniques, Université de Nouakchott Al-Aasriya, Nouveau campus universitaire, BP 5026 Nouakchott, Mauritania. ${ }^{2}$ Unité Mixte de Recherche 216 Mère et enfant face aux infections tropicales, Institut de Recherche pour le Développement (IRD), Faculté de Pharmacie, Université Paris Descartes, 4 avenue de l'Observatoire, 75270 Paris Cedex 06, France. ${ }^{3}$ Service de Pédiatrie, Centre Hospitalier Mère et Enfant (CHME), Nouakchott, Mauritania. ${ }^{4}$ Centre de santé de Teyarett, Nouakchott, Mauritania. ${ }^{5}$ Unité de Parasitologie et d'Entomologie, Institut de Recherche Biomédicale des Armées, IHU-Méditerranée Infection, Marseille, France. ${ }^{6}$ Aix Marseille Univ, IRD, AP-HM, SSA, VITROME, IHUMéditerranée Infection, Marseille, France. ${ }^{7}$ Centre National de Référence du Paludisme, Institut Hospitalo-Universitaire (IHU) Méditerranée Infection, Marseille, France.
} 


\section{Acknowledgements}

The authors express their gratitude to Dr. Mohamed Lemine Ould Khairy, the former coordinator of the national malaria control programme, and Dr. Abdullah Hmeyade, Director of the Hospital Centre of Atar, for facilitating the study.

\section{Competing interests}

The authors declare that they have no competing interests.

\section{Availability of data and materials}

All data generated or analysed during this study are included in this published article and [40].

\section{Consent for publication}

Not applicable.

\section{Ethics approval and consent to participate}

This study protocol was reviewed and approved by the institutional ethics committee of the Université de Nouakchott Al-Aasriya and the institutional ethics committee of the Institut de Recherche pour le Développement, Marseille, France. The purpose of the study was explained in local dialect to adult patients or parents (or legal guardians), who provided informed written consent on behalf of malaria-infected children.

\section{Funding}

This work was supported by research grants from Expertise France (Initiative $5 \%$ grant) and French National Research Institute for Sustainable Development (Institut de Recherche pour le Développement, Jeune Equipe Associée à l'IRD, RI3 M grant). JMD received a Ph.D. scholarship from the French government through the French Embassy in Nouakchott.

\section{Publisher's Note}

Springer Nature remains neutral with regard to jurisdictional claims in published maps and institutional affiliations.

\section{Received: 25 August 2018 Accepted: 24 October 2018}

\section{Published online: 08 November 2018}

\section{References}

1. WHO. World malaria report 2017. Geneva: World Health Organization; 2017

2. Mint Lekweiry K, Basco LK, Ould Ahmedou Salem MS, Hafid JE, MarinJauffre A, OuldWeddih A, et al. Malaria prevalence and morbidity among children reporting at health facilities in Nouakchott, Mauritania. Trans R Soc Trop Med Hyg. 2011;105:727-33.

3. Mint Lekweiry K, Ould Mohamed Salem Boukhary A, Gaillard T, Wurtz N, Bogreau $\mathrm{H}$, Hafid JE, et al. Molecular surveillance of drug-resistant Plasmodium vivax using pvdhfr, pvdhps and pvmdr1 markers in Nouakchott, Mauritania. J Antimicrob Chemother. 2012;67:367-74.

4. Ould Ahmedou Salem MS, Basco LK, Ouldabdallahi M, Mint Lekweiry K, Konaté L, Faye $\mathrm{O}$, et al. Malaria-associated morbidity during the rainy season in Saharan and Sahelian zones in Mauritania. Acta Trop. 2015;152:1-7.

5. Genton B, Mueller I. Vivax malaria: more severe and more resistant. Therapy. 2010;7:39-48.

6. Cui L, Mharakurwa S, Ndiaye D, Rathod PK, Rosenthal PJ. Antimalarial drug resistance: literature review and activities and findings of the icemr network. Am J Trop Med Hyg. 2015;93(3 Suppl):57-68.

7. Noedl H, Se Y, Schaecher K, Smith BL, Socheat D, Fukuda MM. Artemisinin resistance in Cambodia 1 (ARC1) study consortium. Evidence of artemisinin-resistant malaria in western Cambodia. N Engl J Med. 2008:359:2619-20.

8. Ashley EA, Dhorda M, Fairhurst RM, Amaratunga C, Lim P, Suon S, et al. Spread of artemisinin resistance in Plasmodium falciparum malaria. N Engl J Med. 2014;371:411-23.

9. Leang R, Barrette A, Bouth DM, Menard D, Abdur R, Duong S, et al. Efficacy of dihydroartemisinin-piperaquine for treatment of uncomplicated Plasmodium falciparum and Plasmodium vivax in Cambodia, 2008 to 2010. Antimicrob Agents Chemother. 2013;57:818-26.
10. Amaratunga C, Lim P, Suon S, Sreng S, Mao S, Sopha C, et al. Dihydroartemisinin-piperaquine resistance in Plasmodium falciparum malaria in Cambodia: a multisite prospective cohort study. Lancet Infect Dis. 2016;16:357-65.

11. WHO. Antimalarial drug combination therapy. Report of a WHO technical consultation. Geneva: World Health Organization; 2001.

12. Fidock DA, Nomura T, Talley AK, Cooper RA, Dzekunov SM, Ferdig MT, et al. Mutations in the $P$. falciparum digestive vacuole transmembrane protein PfCRT and evidence for their role in chloroquine resistance. Mol Cell. 2000;6:861-71.

13. Djimdé A, Doumbo OK, Cortese JF, Kayentao K, Doumbo S, Djourté Y, et al. A molecular marker for chloroquine-resistant falciparum malaria. N Engl J Med. 2001;344:257-63.

14. Wilson CM, Serrano AE, Wasley A, Bogenschutz MP, Shankar AH, Wirth DF. Amplification of a gene related to mammalian mdr genes in drug-resistant Plasmodium falciparum. Science. 1989;244:1184-6.

15. Foote SJ, Kyle DE, Martin RK, Oduola AM, Forsyth K, Kemp DJ, et al. Several alleles of the multidrug-resistance gene are closely linked to chloroquine resistance in Plasmodium falciparum. Nature. 1990;345:255-8.

16. Gil JP, Krishna S. pfmdr1 (Plasmodium falciparum multidrug drug resistance gene 1): a pivotal factor in malaria resistance to artemisinin combination therapies. Expert Rev Anti Infect Ther. 2017;15:527-43.

17. Peterson DS, Walliker D, Wellems TE. Evidence that a point mutation in dihydrofolate reductase-thymidylate synthase confers resistance to pyrimethamine in falciparum malaria. Proc Natl Acad Sci USA. 1988;85:9114-8.

18. Snewin VA, England SM, Sims PF, Hyde JE. Characterisation of the dihydrofolate reductase-thymidylate synthetase gene from human malaria parasites highly resistant to pyrimethamine. Gene. 1989;76:41-52.

19. Kublin JG, Dzinjalamala FK, Kamwendo DD, Malkin EM, Cortese JF, Martino LM, et al. Molecular markers for failure of sulfadoxine-pyrimethamine and chlorproguanil-dapsone treatment of Plasmodium falciparum malaria. J Infect Dis. 2002;185:380-8.

20. Brooks DR, Wang P, Read M, Watkins WM, Sims PF, Hyde JE. Sequence variation of the hydroxymethyldihydropterin pyrophosphokinase: dihydropteroate synthase gene in lines of the human malaria parasite, Plasmodium falciparum, with differing resistance to sulfadoxine. Eur J Biochem. 1994;224:397-405.

21. Triglia T, Cowman AF. Primary structure and expression of the dihydropteroate synthetase gene of Plasmodium falciparum. Proc Natl Acad Sci USA. 1994;91:7149-53.

22. Triglia T, Menthing JGT, Wilson C, Cowman AF. Mutations in dihydropteroate synthase are responsible for sulfone and sulfonamide resistance in Plasmodium falciparum. Proc Natl Acad Sci USA. 1997;94:13944-9.

23. Korsinczky M, Chen N, Kotecka B, Saul A, Rieckmann K, Cheng Q. Mutations in Plasmodium falciparum cytochrome $b$ that are associated with atovaquone resistance are located at a putative drug-binding site. Antimicrob Agents Chemother. 2000;44:2100-8.

24. Schwöbel B, Alifrangis $M$, Salanti A, Jelinek T. Different mutation patterns of atovaquone resistance to Plasmodium falciparum in vitro and in vivo: rapid detection of codon 268 polymorphisms in the cytochrome $b$ as potential in vivo resistance marker. Malar J. 2003;2:5.

25. Bennett TN, Patel J, Ferdig MT, Roepe PD. Plasmodium falciparum $\mathrm{Na}^{+}$/ $\mathrm{H}^{+}$exchanger activity and quinine resistance. Mol Biochem Parasitol. 2007;153:48-58.

26. Okombo J, Ohuma E, Picot S, Nzila A. Update on genetic markers of quinine resistance in Plasmodium falciparum. Mol Biochem Parasitol. 2011;177:77-82.

27. Ariey F, Witkowski B, Amaratunga C, Beghain J, Langlois AC, Khim N, et al. A molecular marker of artemisinin-resistant Plasmodium falciparum malaria. Nature. 2014;505:50-5.

28. Sirawaraporn W, Sathikul T, Sirawaraporn R, Yuthavong Y, Santi DV. Antifolate-resistant mutants of Plasmodium falciparum dihydrofolate reductase. Proc Natl Acad Sci USA. 1997:94:1124-9.

29. Tahar R, de Pécoulas PE, Basco LK, Chiadmi M, Mazabraud A. Kinetic properties of dihydrofolate reductase from wild-type and mutant Plasmodium vivax expressed in Escherichia coli. Mol Biochem Parasitol. 2001;113:241-9.

30. Korsinczky M, Fischer K, Chen N, Baker J, Rieckmann K, Cheng Q. Sulfadoxine resistance in Plasmodium vivax is associated with a specific amino acid in dihydropteroate synthase at the putative sulfadoxine-binding site. Antimicrob Agents Chemother. 2004;48:2214-22. 
31. Carlton JM, Fidock DA, Djimdé A, Plowe CV, Wellems TE. Conservation of a novel vacuolar transporter in Plasmodium species and its central role in chloroquine resistance of P. falciparum. Curr Opin Microbiol. 2001;4:415-20.

32. Nomura T, Carlton JMR, Baird K, del Portillo HA, Fryauff DJ, Rathore D, et al. Evidence for different mechanisms of chloroquine resistance in 2 Plasmodium species that cause human malaria. J Infect Dis. 2001;183:1653-61.

33. Suwanarusk R, Russell B, Chavchich M, Chalfein F, Kenangalem E, Kosaisavee $\mathrm{V}$, et al. Chloroquine resistant Plasmodium vivax: in vitro characterisation and association with molecular polymorphisms. PLOS ONE. 2007;2:e1089.

34. Melo GC, Monteiro WM, Siqueira AM, Silva SR, Magalhaes BML, Alencar ACC, et al. Expression levels of pvcrt-o and pvmdr-1 are associated with chloroquine resistance and severe Plasmodium vivax malaria in patients of the Brazilian Amazon. PLoS ONE. 2014;9:e105922.

35. Nyunt MH, Han JH, Wang B, Aye KM, Aye KH, Lee SK, et al. Clinical and molecular surveillance of drug resistant vivax malaria in Myanmar (2009-2016). Malar J. 2017;16:117.

36. Silva SR, Almeida ACG, da Silva GAV, Ramasawmy R, Lopes SCP, Siqueira $\mathrm{AM}$, et al. Chloroquine resistance is associated to multi-copy pvcrt-o gene in Plasmodium vivax malaria in the Brazilian Amazon. Malar J. 2018;17:267.

37. Brega S, Meslin B, de Monbrison F, Severini C, Gradoni L, Udomsangpetch $\mathrm{R}$, et al. Identification of the Plasmodium vivax mdr-like gene (pvmdr1) and analysis of single-nucleotide polymorphisms among isolates from different areas of endemicity. J Infect Dis. 2005;191:272-7.

38. Marfurt J, de Monbrison F, Brega S, Barbollat L, Müller I, Sie A, et al. Molecular markers of in vivo Plasmodium vivax resistance to amodiaquine plus sulfadoxine-pyrimethamine: mutations in pvdhfr and pvmdr1. J Infect Dis. 2008;198:409-17.

39. Popovici J, Kao S, Eal L, Bin S, Kim S, Ménard D. Reduced polymorphism in the Kelch propeller domain in Plasmodium vivax isolates from Cambodia. Antimicrob Agents Chemother. 2015;59:730-3.

40. Ould Ahmedou Salem MS, Ould Mohamed Lemine Y, Mint Deida J, Ould Lemrabott MA, Ouldabdallahi M, Ba MDD, et al. Efficacy of chloroquine for the treatment of Plasmodium vivax in the Saharan zone in Mauritania. Malar J. 2015;14:39.

41. Plowe C, Djimde A, Bouare M, Doumbo O, Wellems TE. Pyrimethamine and proguanil resistance-conferring mutations in Plasmodium falciparum dihydrofolate reductase: polymerase chain reaction methods for surveillance in Africa. Am J Trop Med Hyg. 1995;52:565-8.

42. Canier L, Khim N, Kim S, Sluydts V, Heng S, Dourng D, et al. An innovative tool for moving malaria PCR detection of parasite reservoir into the field. Malar J. 2013;12:405.

43. WHO. Susceptibility of Plasmodium falciparum to antimalarial drugs. Report on global monitoring 1996-2004. Geneva: World Health Organization; 2005. http://apps.who.int/iris/bitstream/handle/10665/43302 /9241593466_eng.pdf;jsessionid=F523740E2F75BC484020EBC20ECF7F E9? sequence $=1$. Accessed 21 Aug 2018.

44. Mint Lekweiry K, Ould Ahmedou Salem MS, Basco LK, Briolant S, Hafid J, Ould Mohamed Salem Boukhary A. Malaria in Mauritania: retrospective and prospective overview. Malar J. 2015;14:100

45. Ould Ahmedou Salem MS, Mint Lekweiry K, Mint Deida J, Ould Emouh A, Ould Weddady M, Ould Mohamed Salem Boukhary A, et al. Increasing prevalence of Plasmodium vivax among febrile patients in Nouakchott, Mauritania. Am J Trop Med Hyg. 2015;92:537-40.
46. WHO. Guidelines for the treatment of malaria. 3rd ed. Geneva: World Health Organization; 2015.

47. Sa JM, Nomura T, Neves J, Baird JK, Wellems TE, del Portillo HA. Plasmodium vivax: allele variants of the mdr1 gene do not associate with chloroquine resistance among isolates from Brazil, Papua, and monkey-adapted strains. Exp Parasitol. 2005;109:256-9.

48. Barnadas C, Ratsimbasoa A, Tichit M, Bouchier C, Jahevitra M, Picot S, et al. Plasmodium vivax resistance to chloroquine in Madagascar: clinical efficacy and polymorphisms in pvmdr1 and pvcrt-o genes. Antimicrob Agents Chemother. 2008;52:4233-40.

49. Gama BE, de Oliveira NKA, de Souza JM, Daniel-Ribeiro CT, Ferreirada-Cruz FM. Characterisation of pvmdr1 and pvdhfr genes associated with chemoresistance in Brazilian Plasmodium vivax isolates. Mem Inst Oswaldo Cruz. 2009;104:1009-11.

50. Orjuela-Sanchez P, de Santana Filho FS, Machado-Lima A, Chehuan YF, Costa MRF, Alecrim GM, et al. Analysis of single-nucleotide polymorphisms in the crt-o and mdr1 genes of Plasmodium vivax among chloroquine-resistant isolates from the Brazilian Amazon region. Antimicrob Agents Chemother. 2009;53:3561-4.

51. Kim YK, Kim C, Park I, Kim HY, Choi JY, Kim JM. Therapeutic efficacy of chloroquine in Plasmodium vivax and the pvmdr 1 polymorphisms in the Republic of Korea under mass chemoprophylaxis. Am J Trop Med Hyg. 2011;84:532-4

52. Lu F, Lim CS, Nam DH, Kim K, Lin K, Kim TS, et al. Genetic polymorphism in pvmdr 1 and pvcrt-o genes in relation to in vitro drug susceptibility of Plasmodium vivax isolates from malaria-endemic countries. Acta Trop. 2011;117:69-75.

53. Shalini S, Chaudhuri S, Sutton PL, Mishra N, Srivastava N, David JK, et al. Chloroquine efficacy studies confirm drug susceptibility of Plasmodium vivax in Chennai, India. Malar J. 2014;13:129.

54. Teka H, Petros B, Yamuah L, Tesfaye G, Elhassan I, Muchohi S, et al. Chloroquine-resistant Plasmodium vivax malaria in Debre Zeit, Ethiopia. Malar J. 2008;7:220.

55. Ketema T, Bacha K, Birhanu T, Petros B. Chloroquine-resistant Plasmodium vivax in Serbo town, Jimma zone, south-west Ethiopia. Malar J. 2009:8:177.

56. Ketema T, Getahun K, Bacha K. Therapeutic efficacy of chloroquine for treatment of Plasmodium vivax malaria cases in Halaba district, South Ethiopia. Parasites Vectors. 2011;4:46.

57. Yohannes AM, Teklehaimanot A, Bergqvist Y, Ringwald P. Confirmed vivax resistance to chloroquine and effectiveness of artemether-lumefantrine for the treatment of vivax malaria in Ethiopia. Am J Trop Med Hyg. 2011;84:137-40.

58. Deng S, Ruan Y, Bai Y, Hu Y, Deng Z, He Y, et al. Genetic diversity of the Pvk12 gene in Plasmodium vivax from the China-Myanmar border area. Malar J. 2016;15:528.

59. Wang M, Siddiqui FA, Fan Q, Luo E, Cao Y, Cui L. Limited genetic diversity in the PVK12 Kelch protein in Plasmodium vivax isolates from Southeast Asia. Malar J. 2016;15:537.

60. Tantiamornkul K, Pumpaibool T, Piriyapongsa J, Culleton R, Lek-Uthai U. The prevalence of molecular markers of drug resistance in Plasmodium vivax from the border regions of Thailand in 2008 and 2014. Int J Parasitol Drugs Drug Resist. 2018;8:229-37.

\footnotetext{
Ready to submit your research? Choose BMC and benefit from:

- fast, convenient online submission

- thorough peer review by experienced researchers in your field

- rapid publication on acceptance

- support for research data, including large and complex data types

- gold Open Access which fosters wider collaboration and increased citations

- maximum visibility for your research: over 100M website views per year
}

At BMC, research is always in progress.

Learn more biomedcentral.com/submissions 